\title{
Interprofissionalidade e a construção de protocolos assistenciais: uma aproximação entre a graduação e o serviço de saúde
}

\author{
Patrícia Danielle Feitosa Lopes Soares, Andréa Ribeiro da Costa, André Malcher
}

\begin{abstract}
Resumo
INTRODUÇÃO: o Programa de Educação pelo Trabalho para a Saúde (PET-Saúde) foi instituído pela Portaria Interministerial n. 421/10. Enquanto política indutora formativa tem-se o PET Saúde Redes de Atenção (RAS) - 2013-2015, com objetivos de fomentar a interprofissionalidade. A Universidade Federal do Pará (UFPA) aprovou grupos Rede Cegonha (RC), desenvolvendo por meio de acadêmicos, docentes e profissionais do serviço, ações de educação permanente e o fomento à interprofissionalidade do cuidado, em diferentes cenários, incluindo a atenção primária. OBJETIVOS: apresentar as contribuições do PET-Saúde RAS, mediadas pelo diálogo interprofissional, na construção de protocolo de atenção ao pré-natal de baixo risco. MÉTODOS: construção aprovada pelo Comitê de Ética da UFPA n ${ }^{\circ}$ 1337334. O construir do protocolo emergiu da necessidade dos profissionais preceptores e suas equipes ao encontro dos pressupostos da RC e consonante aos critérios da Organização Mundial de Saúde, por meio de: revisão sistemática da literatura individual e coletiva; diagnóstico situacional; reuniões entre o grupo elaborador-roda de diálogos dos sujeitos supracitados na construção coletiva do cuidado; revisão externa; fluxograma; validação pelos profissionais/usuários; limitações e implantação. As discussões englobaram os diferentes atores envolvidos: acadêmicos de enfermagem, farmácia, fisioterapia, medicina, nutrição, odontologia e terapia ocupacional; docente-tutora e preceptores do PET; profissionais da Estratégia Saúde da Família e gestores de Benevides-Pará. RESULTADOS: a elaboração do protocolo sustentou-se interprofissionalmente, apresentando todos os sujeitos como co-participes, na organização das oficinas; rodas de encontro e estudos dirigidos. Ao final de 02 anos foi elaborado o Protocolo de Atenção ao Pré-natal de baixo risco ao encontro das preconizações de saúde, necessidades epidemiológicas e dos serviços do município e olhares interprofissionais. CONCLUSÕES: a construção do protocolo mediado pelo diálogo interprofissional foi protagonista de aprendizado dos envolvidos, favorecendo o refletir e viver processos que promoveram desenvolver trabalho em equipe com integração e colaboração primando pela qualidade da atenção.

Descritores: Atenção à Saúde, Serviços de Integração Docente-Assistencial, Protocolo, Formação profissional
\end{abstract}

